\title{
BMJ Open Health effects of home energy efficiency interventions in England: a modelling study
}

\author{
Ian Hamilton, ${ }^{1}$ James Milner, ${ }^{2}$ Zaid Chalabi, ${ }^{2}$ Payel Das, ${ }^{3}$ Benjamin Jones, ${ }^{4}$ \\ Clive Shrubsole, ${ }^{3}$ Mike Davies, ${ }^{3}$ Paul Wilkinson ${ }^{2}$
}

To cite: Hamilton I, Milner J, Chalabi Z, et al. Health effects of home energy efficiency interventions in England: a modelling study. BMJ Open 2015;5:e007298. doi:10.1136/bmjopen-2014007298

- Prepublication history and additional material is available. To view please visit the journal (http://dx.doi.org/ 10.1136/bmjopen-2014007298).

Received 26 November 2014 Revised 25 February 2015 Accepted 23 March 2015

\section{(1) crossuat}

${ }^{1}$ UCL Energy Institute, University College London, London, UK

${ }^{2}$ Department of Social \& Environmental Health Research, London School of Hygiene \& Tropical Medicine, London, UK

${ }^{3}$ UCL Institute for Environmental Design and Engineering, University College London, London, UK ${ }^{4}$ Department of Architecture and Built Environment, University of Nottingham, Nottingham, UK

Correspondence to Ian Hamilton; i.hamilton@ucl.ac.uk

\section{ABSTRACT}

Objective: To assess potential public health impacts of changes to indoor air quality and temperature due to energy efficiency retrofits in English dwellings to meet 2030 carbon reduction targets.

Design: Health impact modelling study.

Setting: England.

Participants: English household population.

Intervention: Three retrofit scenarios were modelled: (1) fabric and ventilation retrofits installed assuming building regulations are met; (2) as with scenario

(1) but with additional ventilation for homes at risk of poor ventilation; (3) as with scenario (1) but with no additional ventilation to illustrate the potential risk of weak regulations and non-compliance.

Main outcome: Primary outcomes were changes in quality adjusted life years (QALYs) over 50 years from cardiorespiratory diseases, lung cancer, asthma and common mental disorders due to changes in indoor air pollutants, including secondhand tobacco smoke, $\mathrm{PM}_{2.5}$ from indoor and outdoor sources, radon, mould, and indoor winter temperatures.

Results: The modelling study estimates showed that scenario (1) resulted in positive effects on net mortality and morbidity of 2241 (95\% credible intervals (CI) 2085 to 2397) QALYs per 10000 persons over 50 years follow-up due to improved temperatures and reduced exposure to indoor pollutants, despite an increase in exposure to outdoor-generated particulate matter with a diameter of $2.5 \mu \mathrm{m}$ or less $\left(\mathrm{PM}_{2.5}\right)$. Scenario (2) resulted in a negative impact of $-728(95 \% \mathrm{Cl}-864$ to -592$)$ QALYs per 10000 persons over 50 years due to an overall increase in indoor pollutant exposures. Scenario (3) resulted in $-539(95 \% \mathrm{Cl}-678$ to -399$)$ QALYs per 10000 persons over 50 years follow-up due to an increase in indoor exposures despite the targeting of pollutants.

Conclusions: If properly implemented alongside ventilation, energy efficiency retrofits in housing can improve health by reducing exposure to cold and air pollutants. Maximising the health benefits requires careful understanding of the balance of changes in pollutant exposures, highlighting the importance of ventilation to mitigate the risk of poor indoor air quality.

\section{Strengths and limitations of this study}

- The epidemiological evidence about health effects associated with indoor air pollutants and thermal stress is of varying certainty, though more evidence exists for exposure to outdoor pollution and temperature; therefore, only exposures with strong evidence were used.

- This study uses advanced validated building physics models to determine the change in indoor pollutant and thermal exposures related to energy efficiency retrofits.

- The uncertainty in the exposure responses on estimates of health impacts, such as the estimates for cold-related deaths, the toxicity level of particles derived from indoor sources and mental health, could result in a different balance of pollution impact depending on the assumptions made.

- While offering policymakers a support tool to include health as a criterion when developing and assessing home energy efficiency policy, the results presented here should be viewed with a clear understanding of the limitations associated with a modelling study.

\section{INTRODUCTION}

By 2030, the UK housing stock will undergo major changes to improve its energy performance, ${ }^{1}$ motivated by the need to reduce emissions of greenhouse gases (GHGs), considerations of energy security/cost, and concern about fuel poverty with its presumed link to the UK's large burden of winter/coldrelated mortality and morbidity. ${ }^{2}$ Housing is responsible for one-quarter of total $\mathrm{UK} \mathrm{CO}_{2}$ emissions $^{3}$ and $52 \%$ of this is from space heating. Meeting the UK's ambitious energy efficiency targets will require investments to upgrade the energy performance of nearly all dwellings by 2030. ${ }^{1}$ These changes to housing energy performance will comprise one of the largest natural experiments in the indoor 
environment in the coming decades and these are likely to have major impacts on the indoor environment and population health. ${ }^{4} 5$ To date, health consequences have received limited examination, ${ }^{6}$ though they are increasingly being recognised as an issue by the UK Government. ${ }^{7}$

Properly designed and implemented, actions to improve housing energy performance could have major co-benefits for public health, ${ }^{4}$ although there are risks involved and the possibility of poorly designed interventions leading to unintended consequences (figure 1). ${ }^{8-10}$ Energy efficiency retrofits that alter the fabric heat loss can also increase the air tightness of the dwelling, ${ }^{11} 12$ increasing exposure to indoor-generated pollutants (eg, particulates, mould, radon). Living in cold or inefficient and poorly ventilated homes is linked to a range of health problems. ${ }^{51013}$ Retrofits that improve indoor temperatures may have positive impacts on mental health and cardiorespiratory disease ${ }^{5}$ but could have negative impacts on respiratory conditions due to the increased levels of indoor pollutants. ${ }^{14}{ }^{15}$ In the UK, most of our time is spent indoors and the majority of the health impact of more airtight buildings is likely to occur over the long term through low-dose exposure. ${ }^{16}$

While current English building regulations requires that adequate means of ventilation is provided to dwellings, ${ }^{17}$ there is a lack of guidance for determining the level of ventilation required to protect health before or following an energy efficiency retrofit. ${ }^{18}$ The only guidance that exists relates to the replacement of existing window trickle vents. Ultimately, additional ventilation following a retrofit is left to the discretion of the installer or household. The aim of this study is to illustrate the potential health impact of energy efficiency retrofits under different ventilation settings.

In this paper, we describe the results of a modelling study to quantify changes in exposures in the indoor environment and their associated health consequences attributable to housing energy efficiency retrofits. We do this to characterise possible health-related consequences in need of further scrutiny for the development of national policies and guidance on housing energy efficiency interventions. By doing so, we attempt to gain a better understanding of the trade-offs between risks and benefits for population health.

\section{METHODS}

We developed a household-level model to quantify the principal exposure and health pathways outlined in figure 1. The model comprised two parts:

1. A building physics model of English houses that quantifies indoor winter temperatures, exposures to particle pollution, secondhand tobacco smoke (STS), radon, mould growth and energy demand in relation to the energy performance of the dwelling; and

2. A model of the resulting health impacts based on a combination of life table methods and directly modelled changes in disease prevalence.

The two model components make up the Health Impact of Domestic Energy Efficiency Model (HIDEEM;

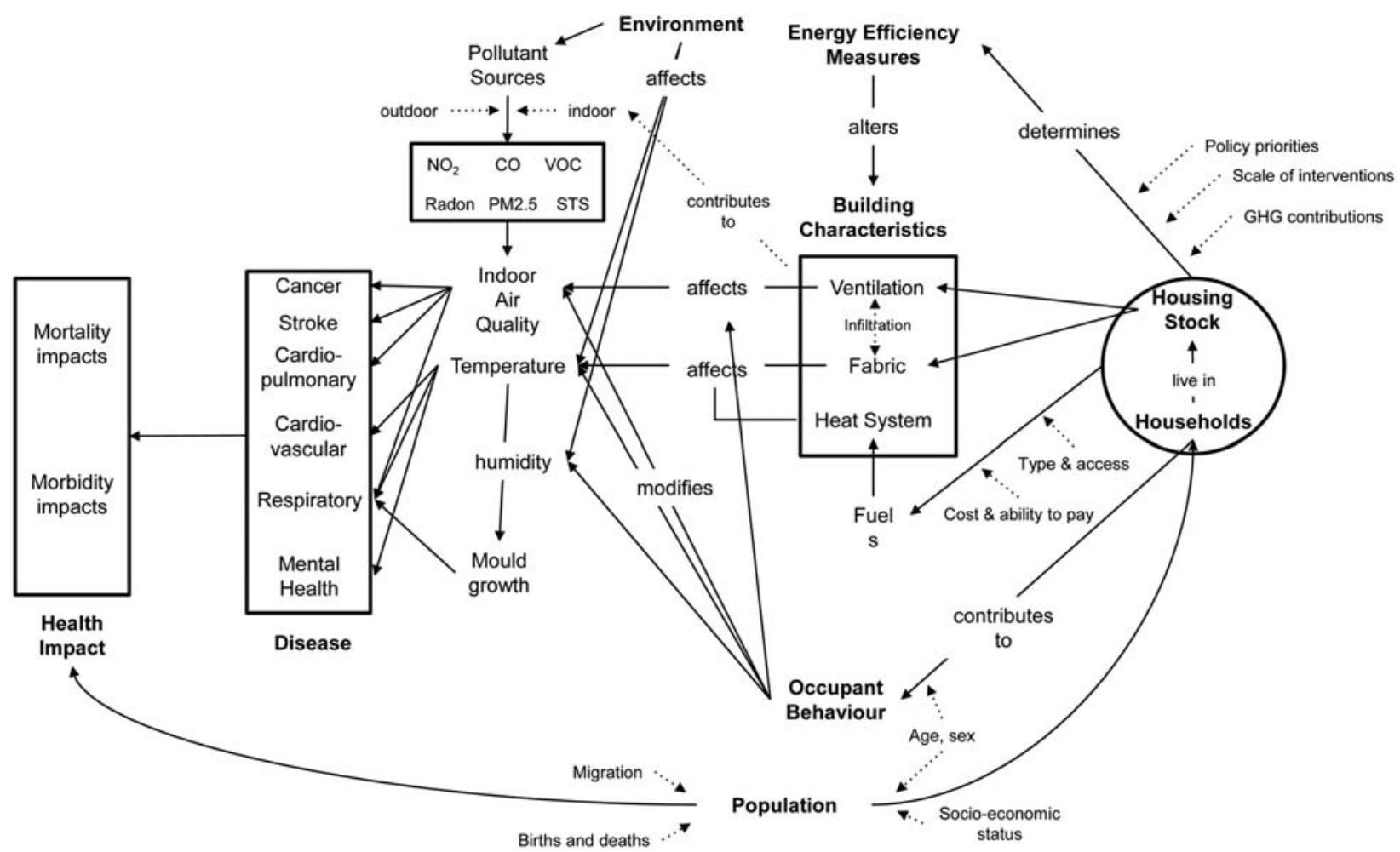

Figure 1 Connections between energy efficiency in housing and health (GHG, greenhouse gas; STS, secondhand tobacco smoke; VOC, volatile organic compound). 


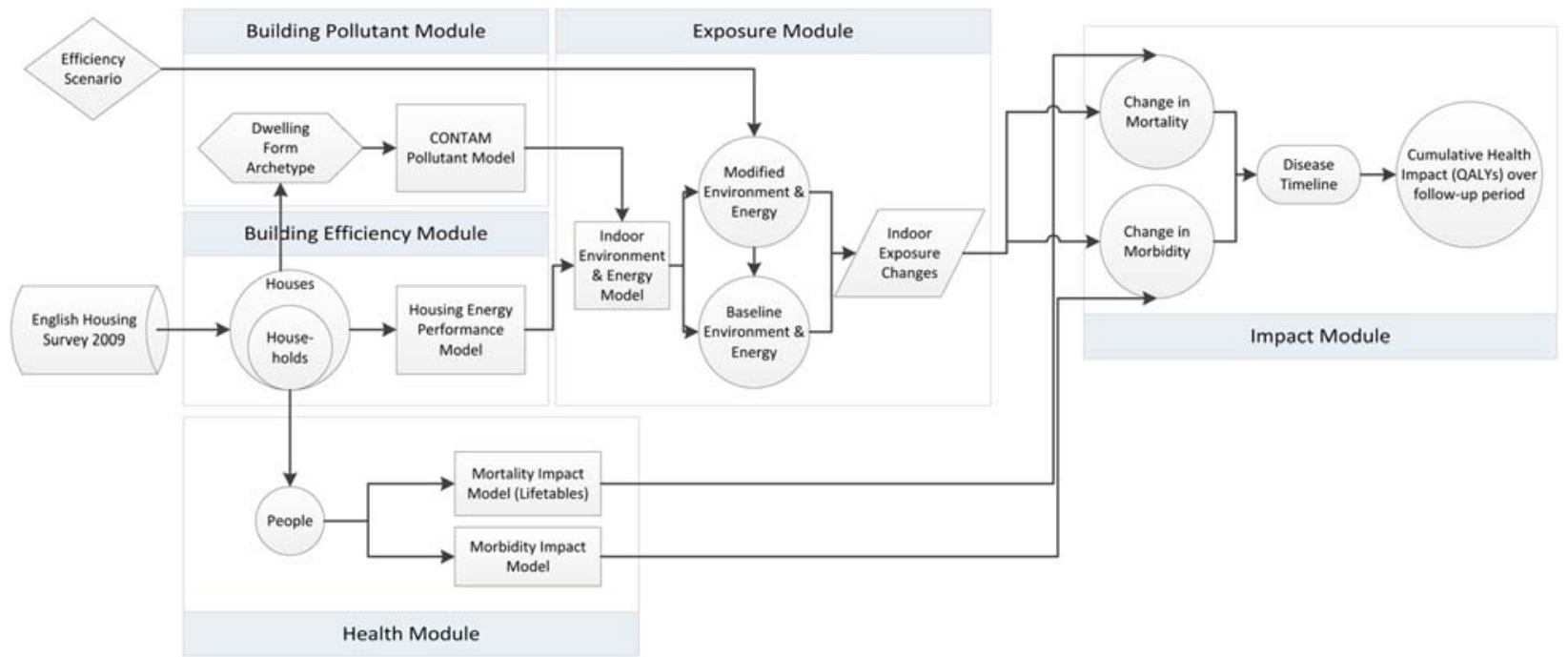

Figure 2 Health Impact of Domestic Energy Efficiency Model (HIDEEM) conceptual framework. The figure demonstrates the components of the model with solid lines representing input flows.

figure 2), an exposure-determinant and health impact model.

Other health outcomes that could be related to energy efficiency interventions but were not considered here include cold-related falls, changes in mental health impact (aside from temperature) and some forms of indoor pollutants (eg, volatile organic compounds, carbon monoxide poisoning, dust mites). However, such evidence can be sparse and the exposure-response uncertain. We have not modelled the impact of cold on respiratory disease (eg, chronic obstructive pulmonary disease) because the evidence required for robust quantification is still equivocal; ${ }^{19}$ we hope to address this in future versions of the model. Also, we have not modelled the risk of overheating on energy efficiency, though this could have an important impact in the future. A difficulty with many empirical studies looking at the health effect of energy efficiency interventions is that the study designs and methods have not been sufficiently robust in their design or controlling for bias so as to draw strong conclusions. ${ }^{5}$

\section{Part 1: Modelling the indoor environment}

We developed a model that characterised the indoor environmental conditions of the 2010 English Housing Survey (EHS). ${ }^{20}$ The indoor environmental conditions and changes in those conditions related to energy efficiency interventions were modelled using validated building physics and airflow models. ${ }^{21-23}$ The modelling, described in detail elsewhere, ${ }^{16} 24{ }^{25}$ used representative archetype dwelling forms (informed by sampling from the EHS ${ }^{26} 27$ ) to represent the English dwelling stock. Each of these archetypes was modelled under different levels of air tightness and ventilation systems: window opening only, window trickle vents, extract fans, and combined use of trickle vents and extract fans. A total of 896 archetypes were modelled and matched to the EHS on the basis of dwelling type (eg, detached, semidetached, terraces and flats), floor area and notional permeability. The result was a model of indoor environmental conditions for a representative sample of English dwellings (see online supplementary appendix 1 for further details).

Dwelling energy performance was calculated as a notional heat loss value. ${ }^{12}$ We used an empirical relationship between the dwelling heat loss value and standardised internal temperature $(\mathrm{SIT})^{\mathrm{i}}$ to predict the bedroom and living room temperature, standardised at an external temperature of $5^{\circ} \mathrm{C}^{12}{ }^{28}$ The SIT is a measure of the thermal condition of the dwelling ranked against all other dwellings, and is a function of the dwelling's energy and ventilation performance. The estimated average SIT (derived from an average temperature of the living room and bedroom) for each dwelling reflects the observed distribution shown in Oreszczyn et al. ${ }^{11}$ The SIT to thermal performance relationship used in the model captures empirical rebound in temperature (eg, reduced heat flow, changes in occupant heating practices and temperature increases). ${ }^{12} \mathrm{We}$ used EHS data on dwelling fabric characteristics, heating system type and presence of ventilation systems to determine eligibility for energy efficiency upgrades (see online supplementary appendix 2).

\section{Part 2: Quantification of health impact}

We focused on a relatively restricted list of exposures that are supported by reasonably clear epidemiological evidence. $^{5}$ The health impact of changes in indoor air

${ }^{\mathrm{i}}$ The standardised internal temperature (SIT) is derived from an empirical study of 1600 English dwellings with half-hourly temperature measurements for a period of 2-4 weeks over the winter period of $2001 / 2002$ and $2002 / 2003$. The SIT is derived from regression models of indoor on outdoor temperature for each dwelling. The models are used to derive a predicted indoor temperature at $5^{\circ} \mathrm{C}$ outdoor temperature. $^{12}$ 
Table 1 Mortality and morbidity outcomes modelled and exposure-response relationships

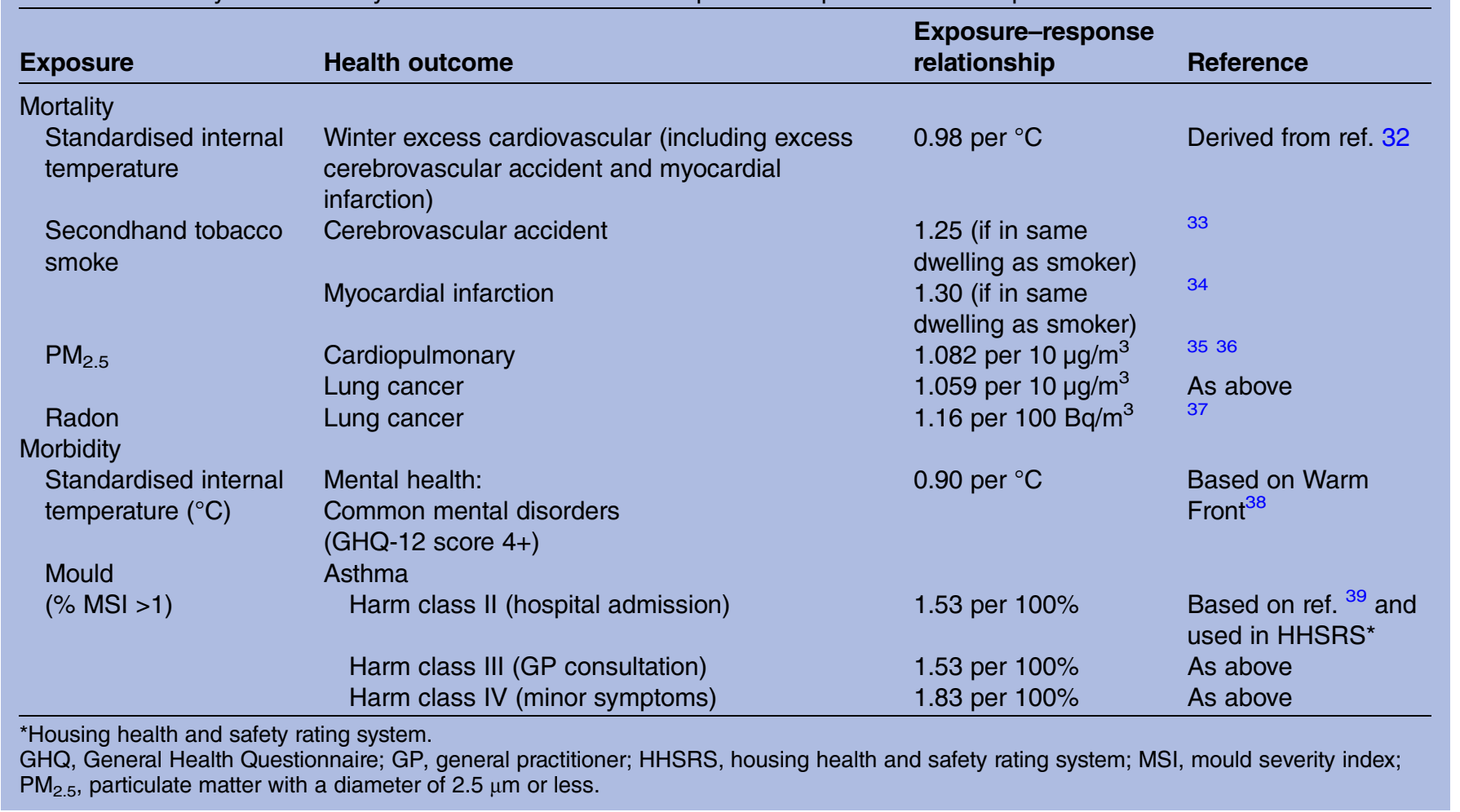

quality and temperature on (cause-specific) mortality was modelled using life table methods based on the IOMLIFET model $^{29}$ but applied to individuals in the EHS data based on their age, sex and specific exposure changes. Life tables were set up using 2010 age-specific population and (disease-specific and all-cause) mortality data for England and Wales from the Office for National Statistics (ONS), with separate life tables set up for males and females. ${ }^{30}$ We modelled changes in five indoor exposures: SIT, STS, indoor and outdoor sources of particulate matter with a diameter of $2.5 \mu \mathrm{m}$ or less $\left(\mathrm{PM}_{2.5}\right)$, radon and mould; the selected outcomes are listed in table 1. Impacts on morbidity for these same outcomes were estimated from the mortality estimates by applying age-specific and cause-specific ratios of years of healthy life lost due to disability (YLD) to the overall years of life lost (YLL) derived from WHO Global Burden of Disease data. ${ }^{31}$

Since some of the outcomes are subcategories of others, to avoid double counting we removed deaths in those subcategories from the larger categories. For outcomes affected by more than one exposure, we assumed the relative risks were multiplicative.

We assumed no time lags for cold-related deaths since these would likely to begin to occur within a year. For the other outcomes, a change in exposure would not necessarily lead to an immediate change in mortality in the population. Therefore, we incorporated diseasespecific time functions to account for disease onset and cessation lags over time. The time lag functions were based on empirical evidence of the effect of smoking cessation on mortality over time, ${ }^{40}$ and plausible assumptions about disease progression over time (see online supplementary appendix 3 ).

We separately estimated morbidity impacts on common mental disorders (CMDs) in adults and asthma in children using published estimates of the underlying disease prevalence in the population to which exposure-related relative risks were applied based on changes in SIT and mould growth, respectively (table 1). Mental health benefit is assumed to persist over 10 years (ie, exponential decay to zero over 10 years).

\section{Model application: 2030 energy efficiency targets}

The model was used to examine the effect of energy efficiency retrofits of the type and order proposed under 2030 GHG mitigation pathways for the English housing sector. ${ }^{1}$ Where dwellings were eligible, the retrofits comprised installing double glazing, insulating cavity and solid walls, adding loft insulation, installing new condensing gas boilers, and adding draught proofing to improve dwelling air tightness in leaky dwellings (air leakage rate $\left.\geq 7 \mathrm{~m}^{3} / \mathrm{m}^{2} / \mathrm{h}\right)$. In addition, non-operational extract fans in the kitchen and bathroom were repaired and window trickle ventilators ${ }^{\text {ii }}$ were installed with glazing upgrades.

We examined three scenarios that addressed ventilation alongside the energy efficiency retrofits (table 2). They were:

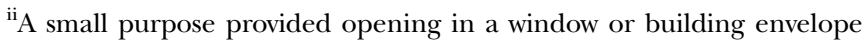
that facilitates ventilation in spaces when large openings (windows and doors) are closed and fans are turned off.
} 
Table 2 Energy efficiency interventions modelled

\begin{tabular}{|c|c|c|c|}
\hline \multirow[b]{3}{*}{ Experiment energy efficiency retrofits } & \multicolumn{3}{|c|}{ Ventilation scenarios } \\
\hline & Regulation & Installer discretion & No added ventilation \\
\hline & \multicolumn{3}{|c|}{ Number of retrofits installed (1000s) } \\
\hline Loft insulation & 5320 & 5320 & 5320 \\
\hline Cavity wall insulation & 6560 & 6560 & 6560 \\
\hline Solid wall insulation & 5700 & 5700 & 5700 \\
\hline Double glazing installation & 2430 & 2430 & 2430 \\
\hline Condensing boiler installation & 10730 & 10730 & 10730 \\
\hline Gas central heating installation & 310 & 310 & 310 \\
\hline Draught proofing & 3870 & 3870 & 3870 \\
\hline Trickle vent and extract fans & 15280 & 900 & 0 \\
\hline Extract fan installation only & 350 & 350 & 0 \\
\hline Extract fan refurbishment & 50 & 50 & 50 \\
\hline Trickle vent installation only & 270 & 270 & 0 \\
\hline
\end{tabular}

1. Purpose provided ventilation via extract fans and trickle vents (where not already present) was installed to ensure adequate indoor air quality in line with regulations (Regulation);

2. Purpose provided ventilation was installed (or repaired) only for dwellings that exhibit problems of mould or inadequate ventilation as reported in the EHS ( 1.16 million dwellings-see online supplementary appendix 1; Installer Discretion); and

3. No purpose provided ventilation was added except for repairing broken extract fans and trickle vents for double glazing to reflect the lack of guidance surrounding energy efficiency retrofits (No Added Ventilation).

We assumed instantaneous installation for all retrofits in order to illustrate the effect of changes in exposures and associated health effect with all other unrelated conditions held constant. We also assumed that no changes occurred in the underlying health status of the population over time, an assumption which previous work has shown to have only a minor effect on life table calculations. ${ }^{41}$

\section{Uncertainty analysis}

We used Monte Carlo simulation to assess parametric uncertainty in the health impact estimates associated with the determinant of the exposure change (ie, the change in heat loss and air tightness due to each intervention), the exposure-response relationships and the utility weights for each health outcome. We report $95 \%$ credible interval estimates based on the 2.5th and 97.5th centiles of results generated from 500 model iterations. $^{42} 43$ See online supplementary appendix 4 for further details.

We also examined the uncertainty of the model due to two important structural assumptions: (1) the length of life lost in those dying of cold-related causes, and (2) the toxicity of particles derived from indoor sources. For cold, assessing chronic health impacts using exposure-response functions based on time series analyses implies that those who are vulnerable to cold-related risks have the same life expectancy as the population average. This is unlikely to be the case; instead it is likely that the people who die of cold-related events are people who have shorter than average life expectancy (see online supplementary appendix 5 for further discussion). To address this, we have examined the effect of assuming that those vulnerable to cold fall into a 'high-risk' subgroup of the population with elevated underlying cardiovascular risk. We then examined the shortening of remaining life expectancy in such a high-risk group as a function of (1) its size as a proportion of the total population (if overall cardiovascular deaths remain the same), and (2) the elevation of risk (relative risk) in the high-risk group compared with the remainder of the population. For particle toxicity, the epidemiology is dominated by studies of outdoor air pollution. However, it is unclear whether the same toxicity should be assumed for particles derived from indoor sources, whose concentration may rise if air tightness is increased. To account for this uncertainty, we performed calculations with and without the inclusion of the estimated effect of particles derived from indoor sources.

There is also uncertainty in the use of the mould severity index (MSI) used in the EHS that is derived from a visual inspection of the occurrence and extent of mould on windows, walls and ceilings. The potential uncertainty of the MSI measurement beyond the simple Monte Carlo treatment of the uncertainty in mould exposure is not examined here.

\section{RESULTS}

\section{Indoor environmental exposure levels}

The 2030 energy efficiency interventions resulted in improvements in energy performance, as well as appreciable increases in air tightness. The changes in indoor air pollutant concentrations reflected the ventilation 
Table 3 Building performance and indoor environment conditions in the English stock for present day (baseline) and cumulative health effect after 50 years for selected exposure-specific diseases under the 2030 energy efficiency retrofit experiment with ventilation scenarios

\begin{tabular}{|c|c|c|c|c|}
\hline & \multirow{2}{*}{$\begin{array}{l}\text { Baseline } \\
\text { Intervention stock }\end{array}$} & \multicolumn{3}{|c|}{ Experiment ventilation scenarios } \\
\hline & & Regulation & Installer discretion & No added ventilation \\
\hline \multicolumn{2}{|l|}{ Sample } & \multicolumn{3}{|l|}{$\mathrm{N}$} \\
\hline \multicolumn{2}{|l|}{ Dwellings (1000s) } & \multicolumn{2}{|l|}{18990} & 17320 \\
\hline \multicolumn{2}{|l|}{ People (1000s) } & & 41130 & 41060 \\
\hline \multicolumn{2}{|l|}{ Building characteristics } & \multicolumn{3}{|l|}{ Mean $\left(\mathrm{SD}^{\star}\right)$} \\
\hline Fabric heat loss (W/K) & $294(167)$ & $219(120)$ & $213(115)$ & $213(116)$ \\
\hline Ventilation heat loss (W/K) & $75(45)$ & $70(42)$ & $51(35)$ & $50(33)$ \\
\hline Heat system efficiency (\%) & $76(12)$ & $88(11)$ & $89(10)$ & $89(10)$ \\
\hline Permeability $\left(\mathrm{m}^{3} / \mathrm{m}^{2} / \mathrm{h}\right)$ & $16(5)$ & $11(5)$ & $11(5)$ & $11(5)$ \\
\hline \multicolumn{2}{|l|}{ Exposure } & \multicolumn{3}{|c|}{ Mean (95\% credibility intervals) } \\
\hline $\begin{array}{l}\text { Standardised indoor } \\
\text { temperature } \ddagger\left({ }^{\circ} \mathrm{C}\right)\end{array}$ & $17.8(0.7)$ & $18.1(18.1,18)$ & $18.1(18.1,18.1)$ & $18.1(18.1,18.1)$ \\
\hline STS§ & $0.5(0.4)$ & $0.5(0.5,0.4)$ & $0.7(0.7,0.6)$ & $0.7(0.7,0.7)$ \\
\hline Indoor $\mathrm{PM}_{2.5}\left(\mu \mathrm{g} / \mathrm{m}^{3}\right)$ & $9.4(5.4)$ & $4.6(4.4,4.2)$ & $10.6(10.1,9.6)$ & $11(10.5,9.9)$ \\
\hline Outdoor $\mathrm{PM}_{2.5}\left(\mu \mathrm{g} / \mathrm{m}^{3}\right)$ & $6.2(1.7)$ & $6.8(6.5,6.2)$ & $5.9(5.6,5.3)$ & $5.8(5.5,5.2)$ \\
\hline Radon $\left(\mathrm{Bq} / \mathrm{m}^{3}\right)$ & $22.9(14.1)$ & $22.4(20.3,20.1)$ & $34.2(30.7,30)$ & $35(31.3,30.7)$ \\
\hline Mould (\% with $\mathrm{MSI}>1$ ) & $14.9(7.5)$ & $12.3(11.6,11)$ & $18.5(17.8,16.2)$ & $18.8(18.3,16.5)$ \\
\hline Heating energy (MWh/year) & $22.9(10.4)$ & $16.6(16.4,16.3)$ & $15.7(15.6,15.4)$ & $15.6(15.5,15.4)$ \\
\hline \multicolumn{2}{|l|}{ Health impact ${ }^{\star \star}$} & \multicolumn{3}{|c|}{ Total QALYs per 10000 persons (95\% credibility intervals)†† } \\
\hline \multicolumn{2}{|l|}{ Cardiovascular (winter) } & $119(106,131)$ & $69(57,81)$ & $65(53,77)$ \\
\hline \multicolumn{2}{|l|}{ Heart attack } & $312(287,336)$ & $-232(-279,-185)$ & $-271(-319,-223)$ \\
\hline \multicolumn{2}{|l|}{ Stroke } & $306(282,330)$ & $-258(-310,-206)$ & $-296(-349,-242)$ \\
\hline \multicolumn{2}{|l|}{ Cardiopulmonary } & $1268(1169,1371)$ & $-44(-83,-6)$ & $-130(-166,-96)$ \\
\hline \multicolumn{2}{|l|}{ Lung cancer } & $233(209,258)$ & $-75(-93,-57)$ & $-97(-115,-81)$ \\
\hline \multicolumn{2}{|l|}{ Common mental disorder } & $2(2,4)$ & $3(3,4)$ & $3(3,4)$ \\
\hline \multicolumn{2}{|l|}{ Asthma (children) } & $1(4,7)$ & $-1(-8,-4)$ & $-1(-9,-5)$ \\
\hline \multicolumn{2}{|l|}{ Net impact } & $2241(2085,2397)$ & $-539(-678,-399)$ & $-728(-864,-592)$ \\
\hline \multicolumn{5}{|c|}{ 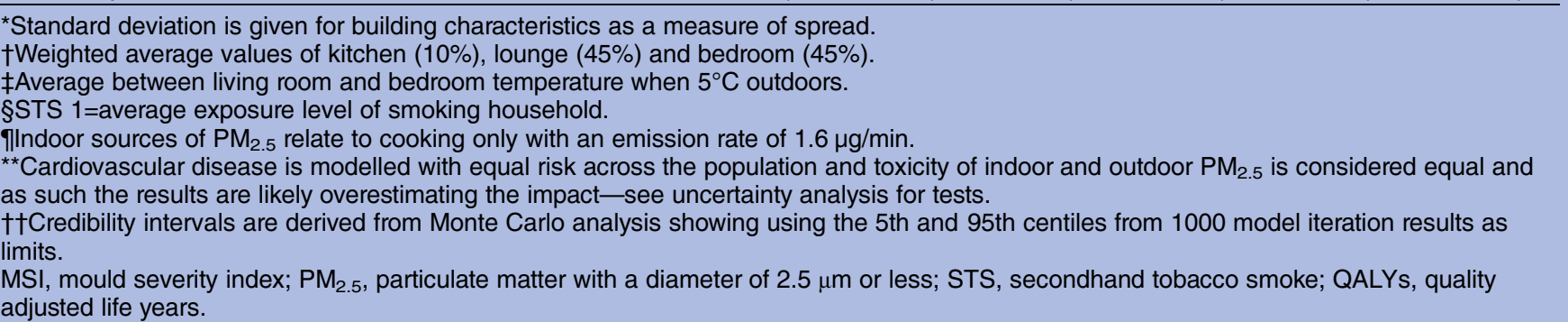 } \\
\hline
\end{tabular}

strategy applied under the three different scenarios.iii Table 3 summarises the energy performance, indoor environmental conditions, changes in exposure levels and health impacts.

Scenario 1 (Regulation), where ventilation systems were added alongside all fabric and heating retrofits, resulted in a $30 \%$ reduction in annual heating energy demand, which is aligned with government objectives. ${ }^{2}$ Wintertime temperatures increased by $0.3^{\circ} \mathrm{C}$ on average (with a SD of \pm 0.5 ), while added ventilation reduced indoor sources of pollutants $\left(53 \%\right.$ for $\mathrm{PM}_{2.5}, 11 \%$ for

\footnotetext{
iii The modelled estimates for the baseline housing stock energy performance and indoor exposures were compared against observed national and sample stock distributions to check the accuracy of the outputs (see online supplementary appendix 1 ).
}

radon, $13 \%$ for STS, $23 \%$ for mould), but increased indoor exposure to outdoor-generated $\mathrm{PM}_{2.5}(4.2 \%)$.

The 'Installer Discretion' scenario shows that mitigation measures applied due to perceptible conditions of inadequate ventilation or mould growth were insufficient to have wide benefit (in part due to the relatively small number of dwellings exhibiting these conditions, see online supplementary appendix 1$)$. With the added ventilation, heat losses (33\%) and heating energy (32\%) were greater compared with the 'Regulation' scenario along with a modest increase in indoor temperatures. Outdoor sources of $\mathrm{PM}_{2.5}$ reduced considerably $(-10 \%)$, but indoor pollutants experienced sizable increases $(8 \%$ for $\mathrm{PM}_{2.5}, 34 \%$ for radon, $33 \%$ for STS and $18 \%$ for mould).

Under the 'No Added Ventilation' scenario, there were still greater reductions in ventilation heat losses. The average indoor pollutant concentrations were 
further elevated across the stock compared with scenario 2 (Installer Discretion).

\section{Health impact of energy efficiency retrofits}

The balance of the overall impact on mortality and morbidity is highly dependent on the assumptions made regarding the level of ventilation to mitigate reduced indoor air quality (table 3; figure 3). Over a follow-up period of 50 years, the net impact of the 2030 energy efficiency interventions under the 'Regulation' ventilation scenario resulted in 2241 quality adjusted life years (QALYs) gained per 10000 persons for the 18.99 million affected dwellings. Selective targeting of ventilation system under the 'Installer Discretion' scenario resulted in -539 QALYs per 10000 persons lost. While no added ventilation had an even greater overall negative impact of -728 QALYs per 10000 persons lost among the intervention group.

If building regulations were met (scenario 1 ), the net impact on health is positive primarily because the reduction in exposure to particles of indoor origin is greater than the increase in outdoor-generated particles. Improved indoor temperatures have a net positive effect on cardiovascular disease, though this is dependent on assumptions of the remaining life expectancy of those vulnerable to the effects of cold (see Uncertainty analysis section).

Targeted extract fans and trickle vents in dwellings with a perceptive ventilation problem (scenario 2) offer only moderate modification on the long-term impact on health, a $30 \%$ improvement from no additional ventilation (scenario 3). However, despite these interventions, there remained a large number of dwellings that experienced an increase in fabric air tightness.
When no additional ventilation was provided alongside the dwelling energy efficiency retrofits, the increase in indoor sources of air pollutants resulted in a net negative impact on health, despite the reduced ingress of outdoor sources of particulates. Although sensitive to assumptions on the equal toxicity of indoor and outdoor $\mathrm{PM}_{2.5}$ (see Uncertainty analysis section), reduced infiltration of outdoor air and increases in exposure to STS, radon and mould risk resulted in a net-negative impact on health.

\section{Uncertainty analysis}

Cold-related deaths risk group size

We use here scenario 2 to illustrate the sensitivity of the health impact estimates to changes in the concentration of cardiovascular risk within the population. Reducing the size of the 'high-risk' cardiovascular group in the population reduces the scale of the health benefit due to increased winter temperatures, though the overall impact is modest (see table 4). We illustrate this by concentrating the risk across increasingly smaller proportions of the population (from $100 \%$ to $0.1 \%$ ), selected to represent the full range of plausible assumptions. An assumption of $100 \%$ of the excess winter cardiovascular deaths being in the high-risk group (ie, the whole population at risk) could result in a considerable overestimate of the change in the burden of winter time cardiovascular disease, while an estimate of $0.1 \%$ (ie, only $0.1 \%$ of the population are at risk) would effectively remove all of the potential benefit of increased temperatures for population health. Pending further research, it is difficult to estimate the correct level of adjustment. However, the impact is almost certain to be appreciably less than that implied by using time series coefficients applied without any correction.
Figure 3 Net mortality and morbidity health effect (quality adjusted life years (QALYs) per 10000 persons) for all selected exposure-specific diseases after 50 years for the 2030 energy efficiency experiment for different ventilation scenarios (arrows denote $95 \%$ credibility intervals). Note: cardiovascular disease is modelled with equal risk across the population and toxicity of indoor and outdoor $\mathrm{PM}_{2.5}$ is considered equal and as such the results are likely overestimating the impact-see 'section, Uncertainty analysis' for tests $\left(\mathrm{PM}_{2.5}\right.$, particulate matter with a diameter of $2.5 \mu \mathrm{m}$ or less).

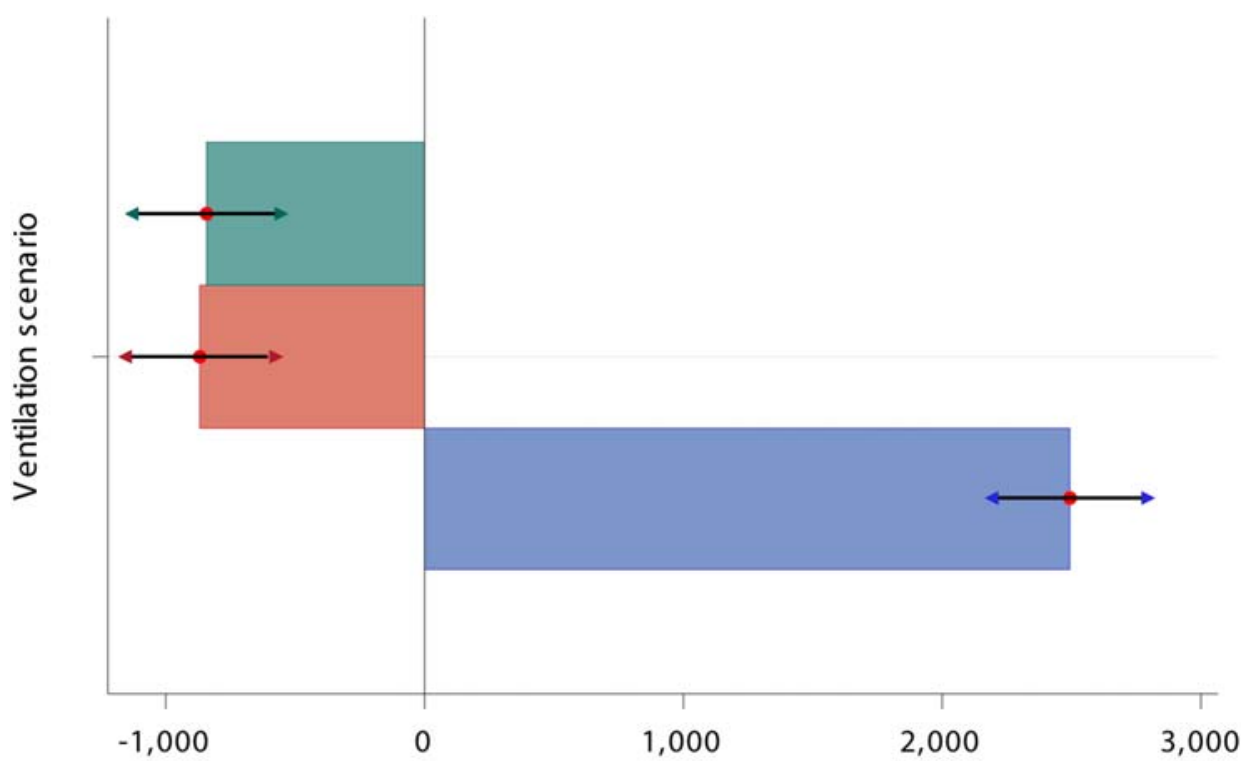

Mean QALYs per 10,000 persons (over 50 years) 


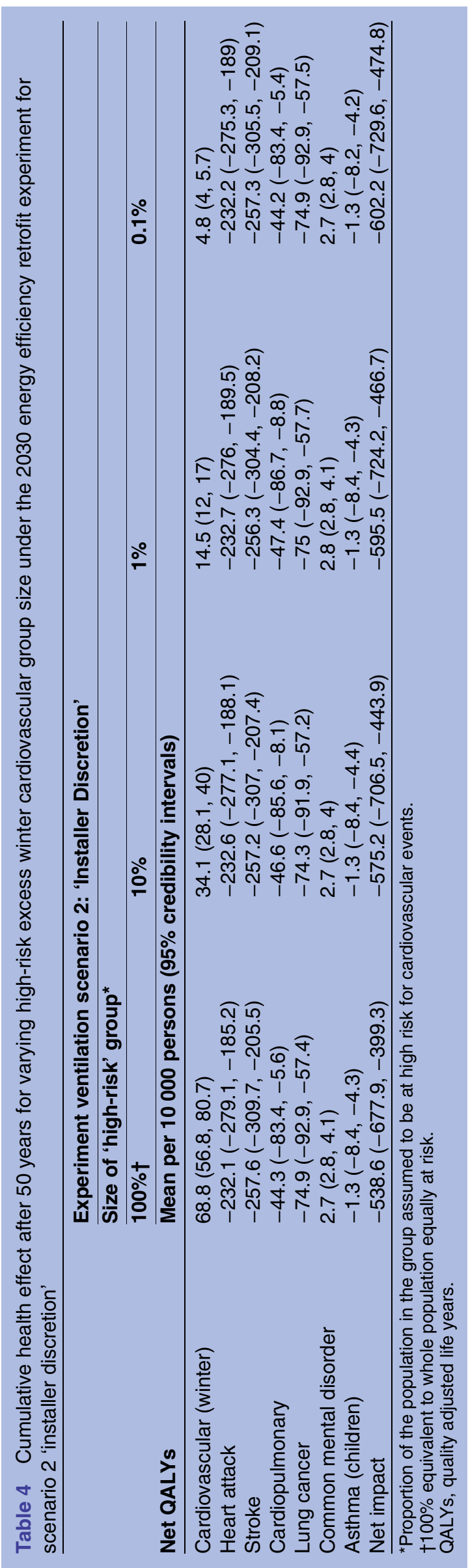

Toxicity of indoor particulate matter

There is uncertainty about the relative toxicity of particles generated from indoor sources compared with those from outdoor sources. Some evidence suggests these might be as toxic or perhaps even more toxic as particulate matter (PM) derived from outdoor sources. ${ }^{35}$ Analysis in which indoor-generated $\mathrm{PM}_{2.5}$ was assumed to have no adverse effect on health had a significant impact on the results (see table 5), reducing the overall net health impact by around $78 \%$ compared with the base case results (which assumed equal toxicity to outdoor particulates). Though the effect may be uncertain, there is very likely to be some impact from indoor sources and we would stress the need for more empirical studies that measure and assess the toxicity of indoor $\mathrm{PM}_{2.5}$, and the balance of indoor and outdoor particles on health.

\section{DISCUSSION}

This modelling work shows that predicted changes in indoor environmental exposures following housing energy efficiency interventions of the type being proposed by the UK Government may have an appreciable impact on health. This approach can be applied to different country settings but with regard to existing conditions, and information on the housing stock and households therein.

There is an expectation that retrofits that seek to reduce space heating energy demand will increase indoor temperatures, ${ }^{12}$ but such interventions will also affect the dwelling air tightness and its ventilation. Although indicative, our modelling suggests that reducing fabric heat loss and increasing air tightness may reduce exposure to outdoor pollutants and raise indoor temperatures. However, without added ventilation, indoor concentrations are increased with associated adverse health impacts which are greater than those associated with indoor temperatures, leading to an overall negative impact on health. As demonstrated, this conclusion is sensitive to assumptions made about the toxicity of particles from indoor sources, an area where further research is urgently needed.

In the various scenarios, for purposes of illustration, we assumed an instantaneous installation and a lagged health impact associated with step changes in some exposures. However, the reality will be that these interventions and potential impacts will be realised over a longer period of time. Under the UK's mitigation targets, virtually all English dwellings will need retrofitting by 2030 (ie, 20 million over 15 years or 3650 per day). Putting in place effective measures to address ventilation now can have long-term health effects for both existing and future households.

Although associations between indoor temperatures and mental well-being have been reported, ${ }^{38}$ it is unclear how long the benefit to mental well-being would persist following improved temperatures. Given the high 
Table 5 Cumulative health effect after 50 years for indoor $\mathrm{PM}_{2.5}$ toxicity equal to outdoor sources and with no effect of indoor $\mathrm{PM}_{2.5}$ under the 2030 energy efficiency retrofit experiment for scenario 2 'installer discretion'

\begin{tabular}{|c|c|c|}
\hline \multirow[b]{4}{*}{ Net QALYs } & \multicolumn{2}{|c|}{ Experiment ventilation scenario 2} \\
\hline & \multicolumn{2}{|c|}{ Indoor particulate matter toxicity } \\
\hline & Equal to outdoor & No effect \\
\hline & \multicolumn{2}{|c|}{ Mean per 10000 persons (95\% credibility intervals) } \\
\hline Cardiovascular (winter) & $68.8(56.8,80.7)$ & $81.6(69.8,93.4)$ \\
\hline Heart attack & $-232.1(-279.1,-185.2)$ & $-186(-225,-147)$ \\
\hline Stroke & $-257.6(-309.7,-205.5)$ & $-212.1(-255.1,-169)$ \\
\hline Cardiopulmonary & $-44.3(-83.4,-5.6)$ & $200.8(170.5,233.5)$ \\
\hline Lung cancer & $-74.9(-92.9,-57.4)$ & $-47(-59.8,-34.5)$ \\
\hline Common mental disorder & $2.7(2.8,4.1)$ & $2.8(2.9,4.1)$ \\
\hline Asthma (children) & $-1.3(-8.4,-4.3)$ & $-1.3(-8.1,-4.2)$ \\
\hline Net impact & $-538.6(-677.9,-399.3)$ & $-161.2(-240.3,-82)$ \\
\hline
\end{tabular}

prevalence of CMD in the population, any small shift can be highly influential on the results. While there is very likely to be benefit that accrues beyond a single year and maybe a seasonal effect for a period afterwards, the long-term benefit will likely be affected by the risk of reoccurring episodes of mental health driven by factors other than thermal environment.

The underlying assumptions regarding housing air tightness and occupant ventilation practices (eg, window opening behaviour) are both extremely important. The EHS shows that $71 \%$ of homes have no extract fans (or working extract fans); in other words, these homes are naturally ventilated and thus, the exposure to indoorgenerated pollutants will be highly determined by the air tightness of the dwelling and the practices of the occupants. Our model has examined the uncertainty of these practices on our estimates and therefore, provides a reasonable spread on the likely true impact. ${ }^{43}$ From our scenarios, we found that added ventilation accompanying efficiency retrofits mitigated the health risk associated with increased air tightness (scenario 1), but that this mitigation must be applied beyond 'problem homes' (scenario 2), only the widespread installation of ventilation systems results in a net benefit to health (scenario 1), and providing no additional ventilation poses a potential risk to health (scenario 3 ).

The provision of added ventilation to offset potential increases in indoor concentrations of pollutants following fabric energy retrofits is an important issue for public health. While the spirit of the building regulations suggests that adequate ventilation should be provided following changes to a dwelling, there is no explicit guidance for installers on what and when to install such systems. The Housing Health and Safety Rating System provides an 'after-the-fact' route through which remediation of poor indoor air quality could be addressed, but it is both unlikely and undesirable to rely on this system to address issues that could otherwise be avoided. Clearly assumptions on how a household ventilates their dwelling will have an important impact on creating a healthy indoor environment. Dwellings with higher ventilation rates have been shown to have reduced health burdens, ${ }^{10} 44$ though the association with air change rates and specific diseases can be equivocal. ${ }^{45}$ Occupant ventilation practices have also been shown to be counter-productive to creating a healthy indoor environment. A study of Dutch households showed that many neglect the annual maintenance required to ensure that ventilation system operation is not compromised. ${ }^{46}$ Education around ventilation will be essential to minimise exposure to indoor pollutants following retrofits. Our work highlights that the potential health impacts following efficiency retrofits are not necessarily positive and that there may be risk trade-offs that will depend on the retrofit installation regulatory framework. Having stronger regulation around energy efficiency retrofits and ventilation will help to realise multiple benefits (eg, energy savings and health).

\section{STRENGTHS AND LIMITATIONS}

Modelling studies provide a method of examining complex problems by drawing together data from a range of sources in order to explore the potential impact of interventions on population health. While quantifying the potential health impact of policy options is preferable over qualitative assessment, doing so is subject to several difficulties, primarily the availability of evidence ${ }^{47}$ and the potential to add scientific credibility to uncertain predictions. ${ }^{48}$ The modelling also involves many uncertainties. For instance, the limited set of observed data on how such retrofits affect indoor air quality remains an impediment, with only a few studies looking at the determinants of indoor air quality (eg, infiltration).$^{5}$ There is a paucity of evidence relating to some of the most important health outcomes-especially in relation to cold. ${ }^{49}$ In the overall balance of health calculations, morbidity impacts are potentially larger than those of mortality, for example, the effect of improved temperatures on $\mathrm{CMD},{ }^{5}$ but the evidence is still uncertain, and this gap in the research evidence should be addressed.

The modelling results are presented as QALYs; however, it is clear that these changes in disease 
outcomes would have an impact on health and social care services beyond these utility estimates. As the average age of the UK population increases so too does the demand on health services. Preventative actions, such as improving energy and ventilation performance, may help to mitigate some of this demand.

The exposure modelling in this experiment concentrated on indoor conditions. The experiment did not alter outdoor pollutant concentrations related to proposed energy supply decarbonisation, ${ }^{1}$ which may reduce outdoor levels of particulate matter in the future. ${ }^{50}$ This would further tip the balance towards installing mitigating ventilation systems so as to dilute 'stale' indoor air. Refining the model to include assumptions on energy systems and transport could further improve the estimates of the potential health impact associated with UK's GHG abatement measures.

\section{CONCLUSIONS AND POLICY IMPLICATIONS}

On balance, if properly implemented, actions to mitigate climate change through energy efficiency in housing can have benefits to health by reducing exposure to cold and outdoor air pollutants. They will also offer indirect health benefits by providing more resilience to protect indoor thermal conditions during extreme cold and heat events. Modelling studies of the type presented here are needed to ensure housing policies are developed in ways that capitalise on this potential for improving health. Such studies, however, should be used with acknowledgment of their uncertainty and limitations, and do not supplant the need for welldesigned empirical studies that can validate models and offer policymakers more evidence, and provide greater confidence around policy impact.

We have shown that, unless specific remediation is used, reducing the ventilation of dwellings will improve energy efficiency at the expense of increased exposure to indoor air pollutants and risk to health. However, an important conclusion of this work is that, with careful attention to retrofit installation and ventilation practices, these potential negative impacts can be removed.

The policy agenda and evidence base on the health impact of home energy efficiency is still evolving. Guidance for installers regarding adequate levels of ventilation to protect health is now needed before the large-scale introduction of energy efficiency measures into the housing stock.

Acknowledgements The following persons were involved in the initial 2009 'Health impact of energy efficiency' DECC funded project-LSHTM: Hutchinson E; Sheffield Hallam University: Wilson I, Green G, Gilbertson J, Stafford B; Warwick University: Ormandy D; Ulster University: Liddell C, Morris C.

Contributors IH developed the integrated health and exposure model, and was responsible for developing the experiment and crafting the text. JM and ZC developed the health model and contributed to the text. PD, BJ and CS all developed portions of the exposure models and contributed to the text.
MD and PW were project leads, guided the study design and contributed to the text.

Funding This work was supported by the European Commission by its 7th Framework Programme Grant Agreement [265325] 'PURGE' project; the Engineering and Physical Sciences Research Council (EPSRC) under grant [EP/I038810/1]; 'EBBS' project, EPSRC, under grant [EP/K011839/1]; 'RCUK Centre for Energy Epidemiology', the Natural Environment Research Council under [NE/I007938/1]; the National Institute for Health Research under [PHR/ 11/3005/31]; and the UK Department of Energy and Climate Change. The corresponding author had full access to all the data in the study and had final responsibility for the decision to submit for publication.

\section{Competing interests None declared}

Provenance and peer review Not commissioned; externally peer reviewed.

Data sharing statement All data used in the study are drawn from publicly available sources, these include: English Housing Survey (UK Data Archive), IOMLIFET (Institute of Occupational Medicine), England and Wales Mortality Data (ONS), and the Warm Front Data (UK Department of Energy and Climate Change (DECC)). Special request to DECC is needed for access to Warm Front.

Open Access This is an Open Access article distributed in accordance with the terms of the Creative Commons Attribution (CC BY 4.0) license, which permits others to distribute, remix, adapt and build upon this work, for commercial use, provided the original work is properly cited. See: http:// creativecommons.org/licenses/by/4.0/

\section{REFERENCES}

1. UK CCC. Fourth carbon budget. London, UK: UK Committee on Climate Change, 2010.

2. DECC. The energy efficiency strategy: the energy efficiency opportunity in the UK. London, UK: Department of Energy and Climate Change, 2012.

3. DECC. UK Emissions Statistics: 2009 final UK greenhouse gas emissions. London, UK, 2011.

4. Wilkinson P, Smith KR, Davies M, et al. Public health benefits of strategies to reduce greenhouse-gas emissions: household energy Lancet 2009;374:1917-29.

5. Thomson H, Thomas S, Sellstrom E, et al. Housing improvements for health and associated socio-economic outcomes. Cochrane Database Syst Rev 2013;(2):CD008657.

6. Joffe M. A framework for the evidence base to support Health Impact Assessment. J Epidemiol Community Health 2002;56:132-8.

7. DECC. Developing DECC's evidence base. London, UK: Department of Energy and Climate Change, 2014.

8. Bone A, Murray V, Myers I, et al. Will drivers for home energy efficiency harm occupant health? Perspect Public Health 2010;130:233-8.

9. Shrubsole C, Macmillan A, Davies M, et al. 100 Unintended consequences of policies to improve the energy efficiency of the UK housing stock. Indoor Built Environ 2014;23:340-52.

10. Sharpe RA, Thornton CR, Nikolaou V, et al. Higher energy efficient homes are associated with increased risk of doctor diagnosed asthma in a UK subpopulation. Environ Int 2015;75:234-44.

11. Oreszczyn T, Ridley I, Hong SH, et al. Mould and winter indoor relative humidity in low income households in England. Indoor built Environ 2006;15:125-35.

12. Oreszczyn T, Hong SH, Ridley I, et al. Determinants of winter indoor temperatures in low income households in England. Energy Build 2006;38:245-52.

13. Shiue I, Shiue M. Indoor temperature below $18^{\circ} \mathrm{C}$ accounts for $9 \%$ population attributable risk for high blood pressure in Scotland. Int $J$ Cardiol 2014;171:e1-2

14. Simoni M, Lombardi E, Berti G, et al. Mould/dampness exposure at home is associated with respiratory disorders in Italian children and adolescents: the SIDRIA-2 Study. Occup Environ Med 2005;62:616-22.

15. Davies $M$, Ucci M, Mccarthy $M$, et al. A review of evidence linking ventilation rates in dwellings and respiratory health. A focus on house dust mites and mould. Int J Vent 2004;3:155-68.

16. Milner J, Shrubsole C, Das P, et al. Home energy efficiency and radon related risk of lung cancer: modelling study. BMJ 2014;348: f7493.

17. HM Government. The Building Regulations 2010. 2010. 
18. HM Government. Approved document F: ventilation (2010 Ed.). London, UK: Stationery Office, 2010.

19. Osman LM, Ayres JG, Garden C, et al. Home warmth and health status of COPD patients. Eur J Public Health 2008:18:399-405.

20. CLG. English Housing Survey, 2010: Housing Stock Data. London, UK: HMSO, 2013.

21. Dols WS, Walton GN. Multizone Airflow and Contaminant Transport Analysis Software (CONTAMW). 2002.

22. Emmerich SJ. Validation of multizone IAQ modeling of residential-scale buildings: a review. ASHRAE Trans, 2001.

23. Hughes M, Palmer J, Cheng V, et al. Sensitivity and uncertainty analysis of England's housing energy model. Build Res Int 2013:41:156-67.

24. Shrubsole C, Ridley I, Biddulph P, et al. Indoor PM2.5 exposure in London's domestic stock: modelling current and future exposures following energy efficient refurbishment. Atmos Environ 2012;62:336-43.

25. Milner J, Hamilton I, Shrubsole C, et al. What should the ventilation objectives be for retrofit energy efficiency interventions of dwellings? Build Serv Eng Res Technol 2015;36:221-9.

26. Mavrogianni A, Wilkinson P, Davies M, et al. Building characteristics as determinants of propensity to high indoor summer temperatures in London dwellings. Build Environ 2012;55:117-30

27. Oikenoumou E, Davies M, Mavrogianni A, et al. The relative importance of the urban heat island and the thermal quality of dwellings for overheating in London. Build Environ 2010;57:223-38.

28. Hamilton IG, Davies M, Ridley I, et al. The impact of housing energy efficiency improvements on reduced exposure to cold-the 'temperature take back factor'. Build Serv Eng Res Technol 2011;32:85-98.

29. Miller BG, Hurley JF. Life table methods for quantitative impact assessments in chronic mortality. $J$ Epidemiol Community Health 2003;57:200-6.

30. ONS. Mortality statistics: deaths registered in 2009. London, UK, 2010.

31. World Health Organization. The global burden of disease: 2004 update. Geneva: World Health Organization, 2008.

32. Wilkinson P, Landon M, Armstrong B, et al. Cold comfort: the social and environmental determinants of excess winter death in England, 1986-1996. York, UK: Joseph Rowntree Foundation, 2001.

33. Lee PN, Forey BA. Environmental tobacco smoke exposure and risk of stroke in nonsmokers: a review with meta-analysis. J Stroke Cerebrovasc Dis 2006:15:190-201.

34. Law MR, Morris JK, Wald NJ. Environmental tobacco smoke exposure and ischaemic heart disease: an evaluation of the evidence. BMJ 1997;315:973-80.
35. Pope CA, Burnett RT, Thun MJ, et al. Lung cancer, cardiopulmonary mortality, and long-term exposure to fine particulate air pollution. JAMA 2002;287:1132-41.

36. Pope CA, Burnett RT, Thurston GD, et al. Cardiovascular mortality and long-term exposure to particulate air pollution: epidemiological evidence of general pathophysiological pathways of disease. Circulation 2004;109:71-7.

37. Darby S, Hill D, Auvinen A, et al. Radon in homes and risk of lung cancer: collaborative analysis of individual data from 13 European case-control studies. BMJ 2005;330:223.

38. Gilbertson J, Grimsley M, Green G. Psychosocial routes from housing investment to health: evidence from England's home energy efficiency scheme. Energy Policy 2012;49:122-33.

39. Fisk WJ, Lei-Gomez Q, Mendell MJ. Meta-analyses of the associations of respiratory health effects with dampness and mold in homes. Indoor Air 2007;17:284-96.

40. Lin H-H, Murray M, Cohen T, et al. Effects of smoking and solid-fuel use on COPD, lung cancer, and tuberculosis in China: a time-based, multiple risk factor, modelling study. Lancet 2008;372:1473-82.

41. Miller B, Hurley JF. Comparing estimated risks for air pollution with risks for other health effects. Edinburgh: Institute of Occupational Medicine, 2006.

42. Scarborough $P$, Nnoaham KE, Clarke D, et al. Modelling the impact of a healthy diet on cardiovascular disease and cancer mortality. $J$ Epidemiol Community Health 2012;66:420-6.

43. Das $\mathrm{P}$, Shrubsole $\mathrm{C}$, Jones $\mathrm{B}$, et al. Using probabilistic sampling-based sensitivity analyses for indoor air quality modelling. Build Environ 2014;78:171-82.

44. Sundell J, Levin $\mathrm{H}$, Nazaroff WW, et al. Ventilation rates and health: multidisciplinary review of the scientific literature. Indoor Air 2011;21:191-204.

45. Bornehag CG, Sundell J, Hägerhed-Engman L, et al. Association between ventilation rates in 390 Swedish homes and allergic symptoms in children. Indoor Air 2005;15:275-80.

46. Balvers $\mathrm{J}$, Bogers $\mathrm{R}$, Jongeneel $\mathrm{R}$, et al. Mechanical ventilation in recently built Dutch homes: technical shortcomings, possibilities for improvement, perceived indoor environment and health effects. Archit Sci Rev 2012;55:4-14.

47. Parry J, Stevens A. Prospective health impact assessment: pitfalls, problems, and possible ways forward. BMJ 2001;323:1177-82.

48. Mindell J, Boaz A, Joffe M, et al. Enhancing the evidence base for health impact assessment. $J$ Epidemiol Community Health 2004;58:546-51.

49. Ormandy D, Ezratty V. Health and thermal comfort: from WHO guidance to housing strategies. Energy Policy 2012;49:116-21.

50. Markandya A, Armstrong BG, Hales S, et al. Public health benefits of strategies to reduce greenhouse-gas emissions: low-carbon electricity generation. Lancet 2009;374:2006-15. 


\section{Correction}

Hamilton I, Milner J, Chalabi Z, et al. Health effects of home energy efficiency interventions in England: a modelling study. BMJ Open 2015;5:e007298. doi: 10.1136/ bmjopen-2014-007298

Some text was missed out of the Acknowledgements in the original paper. The full Acknowledgement statement should read:

Acknowledgements The following persons were involved in the initial 2009 'Health impact of energy efficiency' DECG funded project-LSHTM: Hutchinson E; Sheffield Hallam University: Wilson I, Green G, Gilbertson J, Stafford B; Warwick University: Ormandy D; Ulster University: Liddell C, Morris C; UCL: Ian Ridley. Ian Ridley was also involved in the subsequent 2012 funded work, developing core parts of the pollutant module.

Open Access This is an Open Access article distributed in accordance with the Creative Commons Attribution Non Commercial (CC BY 4.0) license, which permits others to distribute, remix, adapt, build upon this work non-commercially, and license their derivative works on different terms, provided the original work is properly cited and the use is non-commercial. See: http://creativecommons.org/licenses/by-nc/4.0/

BMJ Open 2017;7. doi:10.1136/bmjopen-2014-007298corr1 